by O. W. Richards ; "Principles of Insect Predation", by C. S. Holling; "Biological Control of Pest Insects in Europe", by J. M. Franz; "Sampling Crop Pests and their Hosts", by A. H. Strickland; "Biology of Chiggers", by Manabu Sasa; "The Phenomenon of Industrial Melanism in Lepidoptera", by H. B. D. Kettlewell ; "A Review of the Phylogeny of Mites", by T. A. Woolley; "Palæoentomology", by 0 . Martynova ; "The Analysis of Insect Embryogenesis", by S. J. Counce ; "The Chemistry of Organic Insecticides", by T. R. Fukuto ; "Mode of Action of Insecticides", by C. C. Roan and T. L. Hopkins ; "Ecological Aspects of Plant Virus Transmissions", by W. Carter; "Mechanism of Transmission of Viruses by Mosquitoes", by R. W. Chamberlain and W. D. Sudia; "Arthropod Vectors as Reservoirs of Microbial Disease Agents", by C. B. Philip and W. Burgdorfer; and "Transmission of Filarioid Nematodes", by F. Hawking and M. Worms. In addition there are cumulative indexes to the volumes 2-6 (Why not 1-5 ?).

Not all, however, are equally rewarding to the non-specialist. While most authors interpret the word 'review' to mean a general survey of a field of study, which any interested person might use as a starting point, a few, including one or two in this volume, have moved to the extreme that the editors originally said they wished to avoid : ". . . a mere concatenation of bibliographical summaries or abstracts. ..". An article that can be understood only by people already working in that field would be better placed in a specialized journal.

Apart from these that are a breathless catalogue of new facts, a few others are spoiled by being written in a language that purports to be English, but has to be mentally translated before it can be understood. "Furthermore, lifelong infection of true hibernating mosquitoes may explain, at least in part, the overwintering of virus in colder temperate regions where continuous transmission is interrupted." Why not say : "In colder temperate regions mosquitoes stop biting during the winter, but those that hibernate may act as a winter reservoir for the virus"? H. B. D. Kettlewell on "Industrial Melanism in Lepidoptera" is a model of clarity : "The canopy of all trees is washed by rain and the pollution is carried down the branches, and finally the trunk".

HAROLD OLDROYD

\section{IN SEARCH OF RACE RELATIONS}

\section{White Man}

A Study of the Attitudes of Africans to Europeans in Ghana before Independence. By Dr. Gustav Jahoda. Pp. xii +144 . (London and New York: Oxford University Press, 1961. Issued under the auspices of the Institute of Race Relations.) 21s. net.

$\mathrm{T}$ the confused and confusing field of studies called 'race relations', the general reader and the research student will welcome a book such as this one. Dr. Jahoda has succeeded in making clear the limits of his study pursued in Ghana just before independence, the methods by which he carried it out, and the conclusions he drew from it. This is a notably difficult type of study, by a European, of African attitudes to the white races. Its scientific basis is that of a psychologist who is willing to use not one but several techniques, and to discuss how far they are applicable and wherein lie their limitations.
The chapters can be arranged in three main groups : the history of White contacts with Ghana (chapter 1) ; the main groups of informants, school-children and adults, and the methods used to ascertain and record their views (chapters 2-6); and the final two chapters (7 and 8) in which Dr. Jahoda makes an analysis of the results of the study. He says more than once that he felt himself cramped by the limitations of the space allowed, and this is particularly evident in the final two chapters, whore a fuller discussion, both of the methods of study and the results, would have been advantageous.

Among the many studies of political and economic development now being made in Africa, this figld of 'attitudes' is now, neglected and important. There are two distinct yet related aspects of this problem: the attitudes of Africans to Europeans, and that of Europeans to Africans. Studies have been going on at the University College of Central Africa in both these aspects. There is obviously room in all the African countries for a development of these 'attitudes' studies on a seientific basis, which will be recognized by Africans and Europeans as being valid, objective and yielding results which can be applied to contemporary situations. It is therefore imperative to speed up the process by which African research students can receive the kind of advanced training which will enable them to work as fully equipped colleagues with Europeans. These are not studies to be rushed into in order to provide quick solutions for political and economic relationships. They require the detached, unomotional research which can validate its own methods and justify and explain its results, however unexpected or unpalatable they may appear to Africans or to Europeans.

Dr. Jahoda has provided us in this book with several ideas which form the main theoretical leads in his own work and provide suggestions for further development in subsequent studies. One of these concepts is that of the stereotype held by the members of one race about the members of another, and he emphasizes that this stereotype when acquired is "notoriously resistant to change". This complex of attitudes towards the members of another race is the result of a historical time process, and hence there is an element of "time lag" in the formation and expression of attitudes. This is probably the most outstanding contribution in the present study, and is well worth searching out in all the chapters of the book.

Another factor, illustrated in Chapters 2-5, is the difference in the attitudes of Africans with varying degrees of Western education or none at all. Hence there is no one 'African attitude', and these educationally differentiated attitudes also vary in relation to the stages of political and economic develop. ment.

Thirdly, and this concept calls for anthropological as well as psychological investigation, the Africans in this Ghana study distinguished between the British expatriates with whom they had personal contacts in the country, and the British institutions and culture which had been brought to Ghana over a long historical period. This raises in the field of race-relations studies the fundamental question of how far stereotypes and attitudes depend on personal contacts, and how far on identification with or revolt against an imported culture.

There is no index, but there is a detailed synopsis of all the chapters and a useful selected bibliography. 